\title{
Unconscious Relational Inference Recruits the Hippocampus
}

\author{
Thomas P. Reber, ${ }^{1,2}$ Roger Luechinger, ${ }^{3}$ Peter Boesiger, ${ }^{3}$ and Katharina Henke ${ }^{1,2}$ \\ ${ }^{1}$ Department of Psychology and ${ }^{2}$ Center for Cognition, Learning, and Memory, University of Bern, 3012 Bern, Switzerland, and ${ }^{3}$ Institute for Biomedical \\ Engineering, University and ETH Zurich, 8092 Zurich, Switzerland
}

Relational inference denotes the capacity to encode, flexibly retrieve, and integrate multiple memories to combine past experiences to update knowledge and improve decision-making in new situations. Although relational inference is thought to depend on the hippocampus and consciousness, we now show in young, healthy men that it may occur outside consciousness but still recruits the hippocampus. In temporally distinct and unique subliminal episodes, we presented word pairs that either overlapped ("winter-red", "red-computer") or not. Effects of unconscious relational inference emerged in reaction times recorded during unconscious encoding and in the outcome of decisions made $1 \mathrm{~min}$ later at test, when participants judged the semantic relatedness of two supraliminal words. These words were either episodically related through a common word ("winter-computer" related through "red") or unrelated. Hippocampal activity increased during the unconscious encoding of overlapping versus nonoverlapping word pairs and during the unconscious retrieval of episodically related versus unrelated words. Furthermore, hippocampal activity during unconscious encoding predicted the outcome of decisions made at test. Hence, unconscious inference may influence decision-making in new situations.

\section{Introduction}

We mentally combine distinct experiences to optimize our decisions in new situations. Relational inference can be defined as the ability to combine information from discontiguous past episodes to guide decisions in new situations. Much evidence indicates that relational inference requires hippocampal processing and the conscious encoding/retrieval of episodes (Smith and Squire, 2005). We extend current views by showing that relational inference recruits the hippocampus even when encoding and retrieval are unconscious.

Inference has been studied with paradigms that allow for the conscious encoding and retrieval of episodes (Bunsey and Eichenbaum, 1996; Dusek and Eichenbaum, 1997; Heckers et al., 2004; Preston et al., 2004; Smith and Squire, 2005; Ellenbogen et al., 2007). Participants encode stimulus pairs that contain overlapping elements $(\mathrm{A}-\mathrm{B}, \mathrm{B}-\mathrm{C})$. Pairs are presented in many learning trials for participants to choose one stimulus in a pair over the other. The choice of a stimulus is reinforced, e.g., A is reinforced over B and B over C. At test, new combinations of studied stimuli are presented $(\mathrm{A}-\mathrm{C})$ for participants to choose again one stimulus. For A-C, A is the correct choice. A correct choice enabled by the flexible integration of $\mathrm{A}-\mathrm{B}$ and $\mathrm{B}-\mathrm{C}$ memories is considered true inference (Leo and Greene, 2008), which is thought to depend on the hippocampus (Bunsey and Eichenbaum, 1996; Dusek and Eichenbaum, 1997; Heckers et al., 2004; Preston et al.,

\footnotetext{
Received Nov. 9, 2011; revised March 6, 2012; accepted March 15, 2012.

Author contributions: T.P.R. and K.H. designed research; T.P.R. and R.L. performed research; R.L. and P.B. contributed unpublished reagents/analytic tools; T.P.R. and K.H. analyzed data; T.P.R. and K.H. wrote the paper.

This work was supported by Grant 320000-114012 from the Swiss National Science Foundation to K.H. We thank

Patrizio Colella and Daniel Oppliger for help with data collection and Simon Ruch for critical comments.

The authors declare no competing financial interests.

Correspondence should be addressed to Katharina Henke, Department of Psychology, University of Bern, Muesmattstrasse 45, 3012 Bern, Switzerland. E-mail: henke@psy.unibe.ch.

DOI:10.1523/JNEUROSCI.5639-11.2012

Copyright $\odot 2012$ the authors $\quad 0270-6474 / 12 / 326138-11 \$ 15.00 / 0$
}

2004; Smith and Squire, 2005; Ellenbogen et al., 2007) and hence on episodic (Tulving, 2002) or declarative (Cohen and Eichenbaum, 1993; Reber et al., 1996; Squire and Wixted, 2011) memory. However, a correct choice at test may also result from the learning of simple reward associations ( $\mathrm{A}$ is always rewarded and $\mathrm{C}$ never) that relies on the dopaminergic reward system (Frank et al., 2003, 2006; Libben and Titone, 2008; Moses et al., 2010). In contrast to standard transitive inference paradigms, the premise pairs in the task used by Leo and Greene (2008) did not have endpoints (i.e., there was not one item that was always reinforced and another that was never reinforced). When the influence of a differential reinforcement history was eliminated, there was still evidence for inferential learning, referred to as "true inference."

To avoid reward learning and all sorts of incremental learning altogether and to favor a relational hippocampal processing mode, we omitted reward and confined encoding to one trial. We used an established masking technique (Degonda et al., 2005) to present overlapping $(\mathrm{A}-\mathrm{B}, \mathrm{B}-\mathrm{C})$ and nonoverlapping $(\mathrm{A}-\mathrm{B}$, $\mathrm{C}-\mathrm{D})$ word pairs for unconscious encoding. For retrieval, the previously subliminally presented words were displayed suprathreshold and in new combinations. Words in a retrieval pair were either episodically related, allowing for inference (A-C), or unrelated $(\mathrm{A}-\mathrm{D})$. The inference task was to decide whether the words in a pair fit together semantically. Inference relied on participants' intrinsic analyses of A-B and B-C pairs, which may lead to opposing courses of inference. Episodically related stimuli (A-C) may either be judged as semantically nearer or farther from each other depending on whether the simultaneous association of $\mathrm{B}$ with $\mathrm{A}$ and $\mathrm{C}$ is considered conflicting or agreeing. We refer to an increase of perceived semantic distance as an instance of divergence and to a decrease of perceived semantic distance as convergence. Both convergence and divergence are valid courses of inference in our paradigm. 


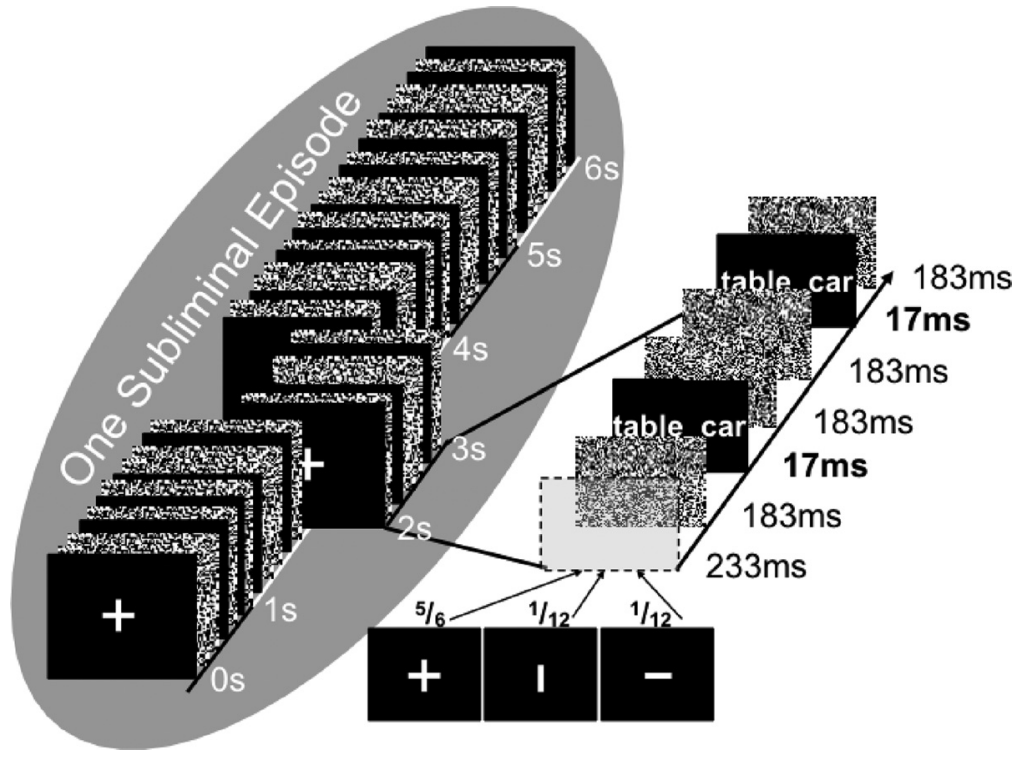

Figure 1. Presentation procedure for one subliminal episode. Each subliminal word pair was presented twelve times in a $6 \mathrm{~s}$ time window, which we call one subliminal episode. Word pairs were flashed for $17 \mathrm{~ms}$ flanked by pattern masks that consisted of random arrangements of black and white pixels. A central fixation cross was presented once a second. Once in $6 \mathrm{~s}$ (i.e., in one subliminal episode), the fixation cross was replaced by a horizontal or vertical bar. Participants performed an attention task that required them to fixate gaze on the central fixation cross and to indicate by button press the occurrence of a horizontal (left key) and vertical (right key) bar. Figure is reproduced from Reber and Henke (2011).

\section{Materials and Methods}

Participants

Thirty-three men were tested. An entirely male sample was tested because men seem to display less diffuse and more lateralized brain activation patterns in language tasks compared with women (Shaywitz et al., 1995). A male sample might therefore benefit the signal-to-noise ratio of bloodoxygen level-dependent (BOLD) signals evoked by the subliminal word pairs. Two participants were excluded because of excessive headmovements in the MR scanner and one participant because he performed above criterion ( $>20$ correct choices of 30 ) on the test of stimulus awareness (see Test of awareness, below). The remaining thirty participants were right-handed young men (mean age, 27.3 years; SD, 5.2 years). They reported a normal or corrected-to-normal visual acuity and neither current nor past neurological or psychiatric diagnoses nor the current consumption of illegal or prescription drugs. All participants were paid for participation and gave written semi-informed consent. The purpose of the study and the presence of subliminal stimuli were disclosed at the end of the session. The study was approved by the local ethics committee.

\section{Stimuli}

We used 96 pairs of concrete German nouns in the main experiment. Sixty-four word pairs were used for subliminal encoding and 32 word pairs were used for the supraliminal test. Test word pairs were novel combinations of words used for subliminal encoding. Half of the encoding word pairs shared a word (see below). The mean number of characters per word was $6.52(\mathrm{SD}, 2.25)$ and the mean logarithm of frequency of use was 2.53 (SD, 0.98). For the direct test of awareness, we selected another set of 60 concrete German nouns, of which 30 were used as targets and 30 as distracters. The words used in the awareness test had a similar mean number of characters per word $(6.69 ; \mathrm{SD}, 1.83)$ and a similar mean logarithmic frequency of use $(2.709$; SD, 0.927) as in the main experiment ( $p s>0.1$ ). The frequency of use was determined using the corpus Projekt Deutscher Wortschatz (for a detailed description of the database, see Biemann et al., 2004).

Nouns assembled in encoding word pairs were semantically distant to provoke the unconscious establishment of new semantic associations in (unconscious) episodic memory. In the experimental condition, two encoding word pairs shared a word (A-B, B-C; e.g., winter-red, red-computer). The corresponding test word pairs consisted of a novel combination of encoding words (A-C; e.g., winter-computer). Thus, the two words in test pairs of the experimental condition were episodically related through an overlapping encoding word (B; e.g., red). For the control condition, corresponding encoding word pairs did not share a word (A-B, C-D; e.g., sockssushi, beard-dust). Again, the corresponding test word pairs were novel combinations of the encoding words (A-D; e.g., socks-dust). Unlike the experimental condition, however, test pairs in the control condition lacked episodic relatedness established during encoding.

Two counterbalanced lists of stimuli were created. Half of the participants received Stimulus List 1 and the other half received Stimulus List 2. Both lists contained stimuli for the experimental condition and stimuli for the control condition. The test stimuli in the two lists were identical. But their encoding history was different because overlapping encoding word pairs in the experimental condition in List 1 became nonoverlapping encoding word pairs in the control condition in List 2. To this aim, the overlapping encoding words in the first list were replaced by new words (List 1: winterred, red-computer $\rightarrow$ List 2: winter-red, tulip-computer). The corresponding test pairs (winter-computer) were therefore identical in both lists but were either episodically related (List 1) or unrelated (List 2). Conversely, an overlap was introduced in the nonoverlapping encoding word pairs of List 1 to obtain overlapping encoding word pairs for List 2 (List 1: socks-sushi, beard-dust $\rightarrow$ List 2: socks-sushi, sushi-dust). The corresponding retrieval pair (socks-dust) was therefore either unrelated (List 1) or episodically related (List 2). This procedure ensured that, over all participants, each retrieval word pair was presented an equal number of times in the experimental and the control condition. Hence, when participants were deciding whether the words in a retrieval pair fit together semantically, a greater number of "fit" responses in one versus the other condition could not be derived from a stimulus bias.

For the baseline condition, we formed 48 pairs of consonant strings (e.g., brtmzh-nvpthw), of which 32 were used in the encoding part and 16 in the retrieval part of the experiment. Consonants were randomly chained in each string. The length of consonant strings was seven letters.

\section{Subliminal stimulus presentation}

We used the masking technique of Degonda et al. (2005), Duss et al. (2011), and Reber and Henke (2011). Each subliminal stimulus pair was presented 12 times in a $6 \mathrm{~s}$ window, flanked by visual noise masks (Fig. 1). We consider this $6 \mathrm{~s}$ presentation of a stimulus pair as one subliminal episode. Presentation durations were $17 \mathrm{~ms}$ for stimuli (S), $183 \mathrm{~ms}$ for masks (M), and $233 \mathrm{~ms}$ for fixation crosses/bars (F). The presentation of one stimulus was given in the following sequence $\mathrm{F}-\mathrm{M}-\mathrm{S}-\mathrm{M}-\mathrm{M}-\mathrm{S}-\mathrm{M}-$ F-M-S-M-M-S-M-F-M-S-M-M-S-M-F-M-S-M-M-S-M-F-MS-M-M-S-M-F-M-S-M-M-S-M. For the attention task, a fixation cross or a bar was presented at a frequency of $1 \mathrm{~Hz}$ during subliminal runs. Once in six presentations or during one subliminal episode, the fixation cross was randomly replaced by a vertical or horizontal bar. The probability of the occurrence of a horizontal or a vertical bar was equal. Participants' task was to indicate the bar's orientation by button press immediately on its occurrence. They pushed the left button for horizontal bars and the right button for vertical bars. Accuracy and reaction times to horizontal and vertical bars were recorded. To conceal the purpose of the masking sequence, subjects were informed that the masking sequence measured attention alone.

Subliminal stimuli spanned a visual angle of $11^{\circ}$ (height) $\times 13^{\circ}$ (width). The software Presentation (http://www.neurobs.com/presentation) was used for stimulus presentation. A BenQ SP831 DLP projector projected the 
computer-controlled stimulation $(1024 \times 768$ resolution, 30-bit color depth, $60 \mathrm{~Hz}$ refresh rate) on a white screen, which was located in front of the subject laying in the MR scanner.

\section{Behavioral paradigm}

The experiment took place in the completely darkened MRI chamber. Stimuli were projected onto a screen located in front of the scanner that participants could see through a mirror, which was attached to their head coil. To get acquainted with task procedures, participants practiced tasks with different stimuli before the experiment started. The experiment consisted of four runs (fMRI time series). Each run contained an encoding and retrieval part. Stimuli were presented blocked by condition.

Encoding. In the encoding part of each run, eight overlapping word pairs $(\mathrm{A}-\mathrm{B}, \mathrm{B}-\mathrm{C}$; experimental condition) and eight nonoverlapping word pairs (A-B, C-D; control condition), as well as eight pairs of consonant strings (baseline condition) were presented for subliminal encoding (Fig. 2). Added over the four runs, we presented a total of 32 stimulus pairs per condition. Stimuli were arranged by condition in blocks of four. Each run contained two encoding blocks per condition. The subliminal presentation of each stimulus pair took $6 \mathrm{~s}$ (no interstimulus interval), which provided for block durations of $24 \mathrm{~s}$. Sixty-six seconds or 11 intervening subliminal word pairs separated A-B from B-C pairs presented in the experimental condition and $\mathrm{A}-\mathrm{B}$ from $\mathrm{C}-\mathrm{D}$ pairs presented in the control condition. During the presentation of subliminal stimuli, participants engaged in the attention task (see Subliminal stimulus presentation, above). The attention task ensured central visual fixation and the maintenance of attention. An instruction slide was presented for $6 s$ at the beginning of the encoding and the retrieval part in each run.

Retrieval. Retrieval followed encoding immediately in each of the four runs (Fig. 2). Each run included four pairs of episodically related words $(A-C)$ in the experimental condition, four pairs of unrelated words (A-D) in the control condition, and four pairs of new letter strings in the baseline condition. Each stimulus pair was presented for $3.5 \mathrm{~s}$ followed by a $1 \mathrm{~s}$ presentation of a blank screen. Because stimulus pairs were again arranged in blocks of four, the retrieval part consisted of only three blocks. Added over the four runs, we presented a total of 16 retrieval pairs per condition.

Words presented in the experimental and control conditions were "old" because they had been presented subliminally during the encoding part of the same run. However, their pairwise combination was new. In the experimental condition, $A$ was indirectly related to $C$ through $\mathrm{B}$, because $\mathrm{B}$ was the common word in $\mathrm{A}-\mathrm{B}$ and $\mathrm{B}-\mathrm{C}$ pairs during encoding. In the control condition, words in a pair were not related. The indirect retrieval task required participants to decide whether the words in an A-C or A-D pair fit together semantically ("fit", left key; "don't fit", right key). Participants were asked to adopt a loose response criterion to achieve an equal amount of "fit" and "don't fit" responses. The temporal distance between the last encoding word pair (B-C or C-D pair) and the corresponding retrieval word pair (A-C or A-D pair) ranged between 55.5 and $72 \mathrm{~s}$. The variability of this interval was due to the difference in presentation durations between encoding and retrieval word pairs and to the difference in the order of condition blocks between participants. Although this time interval varied, there were always 11 intervening subliminal or supraliminal stimulus pairs between the last encoding word pair and the corresponding retrieval word pair.

Order of condition blocks and stimuli in condition blocks. The sequence of condition blocks was varied between runs according to a Latin-square design to distribute position effects of conditions between runs and participants. A given order of condition blocks was maintained throughout the encoding and retrieval part per run. The position within condition blocks was maintained for corresponding word pairs (A-B, B-C, A-C) within a run.

\section{Test of awareness}

Following the experiment, participants were interviewed on whether they had suspected or even perceived subliminal stimuli or perceptual fragments thereof. Then participants underwent the awareness test, where stimulus discriminability was assessed objectively. Standard procedure to establish a claim of unconscious processing is to demonstrate effects of subliminal stimuli in indirect tests (as used in the experiment) in the absence of significant stimulus discrimination in a direct test (Cheesman and Merikle, 1984; Snodgrass and Shevrin, 2006). Our direct test was conducted in the MR scanner and consisted of 30 trials. In each trial, we presented one subliminal word at the same screen location where the right-hand word in the word pairs presented in the experiment had appeared. Thus, due to participants' central visual fixation, we stimulated their left (language-dominant) hemisphere. The reason why we presented one instead of two words (as in the experiment) was to facilitate subliminal processing by reducing the amount of simultaneously displayed information and by eliminating the effect of interhemispheric inhibition on the simultaneous word processing within each hemisphere (Cook, 1986). We figured that conscious awareness of subliminal word pairs could safely be excluded in the experiment if even single words could not be discerned in the final awareness test. Apart from presenting only one instead of two words, the presentation procedure for a subliminal stimulus was the same as in the experiment: each word was presented in one subliminal episode, i.e., in 12 flashes of $17 \mathrm{~ms}$ each, flanked by pattern masks and intermixed with fixation crosses or bars for the attention task. The participants pushed the left or right button immediately upon occurrence of a horizontal or vertical bar, respectively (attention task). Concurrent to the performance of the attention task, the participants were instructed to try to decipher the subliminal word. Immedi- 
ately following the presentation of one word in one subliminal trial, participants chose between a target and a distracter word (forced-choice test). We excluded participants from the analysis of the data from the experiment if they had $>20$ of potentially 30 correct choices in this awareness test. Twenty correct choices corresponded to the $5 \%$ cutoff of the chance distribution of correct choices. One participant exceeded this criterion and was therefore excluded from the analysis of the data of the experiment.

\section{MR image acquisition}

The experiment was performed on a 1.5 tesla Philips Achieva whole-body magnetic resonance scanner equipped with an eight-channel head coil. We obtained functional data by using a sensitivity-encoded single-shot echo planar imaging sequence with an acceleration factor of $r=2.0$ (Schmidt et al., 2005). Thirty-four slices along the AC-PC line were acquired, covering the whole brain with a field of view of $22 \times 22 \mathrm{~cm}$ and a measured spatial resolution of $2.75 \times 2.75 \times 4 \mathrm{~mm}^{3}$ (original voxel size). The reconstructed resolution was $1.72 \times 1.72 \times 4 \mathrm{~mm}^{3}$ (reconstructed voxel size). The time of repetition (TR) was $3 \mathrm{~s}$, echo time (TE) was $50 \mathrm{~ms}$, and flip angle $\theta$ was $90^{\circ}$. There were no interslice gaps. A standard 3D T1-weighted scan was obtained for anatomical reference [TE, $3.8 \mathrm{~ms}$; TR, $8.2 \mathrm{~ms}$; flip angle $\theta, 8^{\circ}$; 160 slices; original voxel size, $1 \times$ $1 \times 1 \mathrm{~mm}$ (no interpolation); field of view, $=24 \times 24 \mathrm{~cm}$, no interslice gaps].

\section{Analysis of functional brain images}

The fMRI data were analyzed using the statistical parametric mapping toolbox (SPM5; http://www.fil.ion.ucl.ac.uk/spm/). Preprocessing included spatial realignment, slice-timing correction, coregistration of EPI images to the participants anatomical reference image, normalization of EPI images into a standard anatomical space [mean image of 152 subjects from the Montreal Neurological Institute (MNI)], and spatial smoothing with $8 \mathrm{~mm}$ Gaussian kernel. Furthermore, the art-repair toolbox (http:// cibsr.stanford.edu/tools/ArtRepair/ArtRepair.htm) was used to detect functional volumes with excessive scan-to-scan movement and global signal variations. Such outlier volumes ( $>2 \mathrm{~mm}$ movement per TR) were replaced by an interpolation of the image before and after the outlier in the time series.

First-level models were estimated separately for encoding and retrieval. These models included regressors that were created by convolving a canonical hemodynamic response function and its temporal derivative with boxcar functions of the onsets and offsets of the conditions for each of the four runs. We also included six movement regressors. Contrast images of paired sample $t$ tests of interest (encoding: B-C vs C-D; retrieval: $\mathrm{A}-\mathrm{C}$ vs $\mathrm{A}-\mathrm{D}$ ) that treated the temporal derivative and movement regressors as nuisance were subjected to random effects analyses. Commonalities in brain activation between subgroups of participants (convergent and divergent thinkers) were assessed using conjunction analyses against the global-null hypothesis (Price and Friston, 1997). Differences in brain activation between subgroups of participants were assessed with independent samples $t$ tests. We used a one-sample $t$ test model with one covariate (i.e., the behavioral measure) to compute correlations between the BOLD signal change and behavioral performance. Effects of this covariate are reported. The height threshold for all fMRI group analyses was $p=0.001$ (uncorrected). No cluster extent threshold was applied for medial temporal lobe regions. For the rest of the brain, we used an extent threshold of 20 voxels.

\section{Results}

\section{Good performance on attention task}

During the unconscious encoding of subliminal word pairs, participants engaged in an attention task that required them to indicate by button press when a repeatedly presented central fixation cross flipped into a horizontal or vertical bar. The number of correct answers in this task was high (mean, 95.4\%; $\mathrm{SD}, 3.6 \%$ ), which indicates that participants were paying close attention to the display on which subliminal stimuli were presented for encoding.

\section{Reaction times at test indicate successful relational integration}

We computed a repeated-measures ANOVA with the factors Test Condition (episodically related vs unrelated), Response ("fit" vs "don't fit"), and the dependent variable reaction time (RT) on the semantic relatedness judgments. The main effect of Test Condition revealed that $\mathrm{RT}$ s to episodically related A-C pairs were longer (mean, $2126 \mathrm{~ms}$; SD, $378 \mathrm{~ms}$ ) than RTs to unrelated A-D pairs (mean, $2064 \mathrm{~ms}$; SD, $362 \mathrm{~ms} ; F_{(29,1)}=6.62, p=0.015$ ). This result indicates that participants were capable of discriminating between episodically related and unrelated test words. Additional processing was apparently needed for the reactivation of $\mathrm{A}-\mathrm{B}$, $\mathrm{B}-\mathrm{C}$, and $\mathrm{A}-\mathrm{B}-\mathrm{C}$ associations in the experimental condition. The main effect of Response was also significant $\left(F_{(1,29)}=6.954\right.$, $p=0.013)$ and indicated that "fit" responses were generally faster (mean, $2039 \mathrm{~ms}$; SD, $338 \mathrm{~ms}$ ) than "don't fit" responses (mean, 2152 ms; SD, 428 ms). The interaction of Response $\times$ Test Condition was not significant $\left(F_{(1,29)}=1.838, p=0.186\right)$, which suggests that the reaction time difference between conditions was not modulated by the kind of response ("fit" vs "don't fit"). This reaction time difference was independent of the direction of inference (convergence vs divergence; see below).

\section{Accuracy at test indicates convergent and divergent styles of relational inference}

The information provided in overlapping encoding pairs (A-B, $\mathrm{B}-\mathrm{C}$ ) is ambiguous with regard to the semantic relatedness of $\mathrm{A}$ and $\mathrm{C}$ words. $\mathrm{A}-\mathrm{B}$ encoding pairs may be considered conflicting with B-C encoding pairs, giving rise to "don't fit" responses to $\mathrm{A}-\mathrm{C}$ test pairs. We designate this style of inference as divergent. Conversely, A-B encoding pairs may be considered agreeing with $\mathrm{B}-\mathrm{C}$ encoding pairs, giving rise to "fit" responses to A-C test pairs. We designate this style of inference as convergent.

The earliest time point during the experiment, at which participants may make divergent or convergent inferences, is when subliminal $\mathrm{B}-\mathrm{C}$ pairs are being presented. At this time, participants may reactivate previously formed $\mathrm{A}-\mathrm{B}$ associations because they are cued by the subliminal B words. We thought of the possibility that reaction times obtained on the attention task concurrent to subliminal encoding could be informative of whether subliminal word pairs $(\mathrm{B}-\mathrm{C})$ were analyzed as conflicting (divergence) or agreeing (convergence) with previously presented word pairs (A-B). Thus, we computed the difference in reaction times on the attention task between periods of subliminal B-C trials (experimental condition) and periods of subliminal C-D trials (control condition): $\mathrm{RT}$ during $\mathrm{B}-\mathrm{C}$ trials minus $\mathrm{RT}$ during $\mathrm{C}-\mathrm{D}$ trials. A positive RT difference shows slower reactions in the attention task during the experimental than the control condition.

The second time point during the experiment, at which participants may make divergent or convergent inferences, is at test, when they engage in the semantic relatedness task judging episodically related A-C pairs (experimental condition) and unrelated A-D pairs (control condition). Divergent thinkers should give more "don't fit" responses to $\mathrm{A}-\mathrm{C}$ than $\mathrm{A}-\mathrm{D}$ pairs, while convergent thinkers should give more "fit" responses to A-C than $\mathrm{A}-\mathrm{D}$ pairs. We computed the difference in the number of "fit" responses between A-C and A-D pairs (number of "fit" responses to A-C pairs minus number of "fit" responses to A-D pairs). A negative difference shows less "fit" responses to A-C pairs (experimental condition) versus A-D pairs (control condition). Negative versus positive values then suggest a divergent versus convergent style of inference. Note that these values are reciprocal to the values of "don't fit" responses. 
The difference in reaction times on the attention task was significantly correlated with the difference in the number of "fit" responses $(r=-0.429, p=0.018$; Fig. 3 ). Slowed reactions in the attention task during the processing of subliminal overlapping $\mathrm{B}-\mathrm{C}$ pairs versus nonoverlapping $\mathrm{C}-\mathrm{D}$ pairs predicted a larger number of "don't fit" responses to episodically related A-C pairs than unrelated A-D pairs. The significance of this correlation between our two measures of inference supports the notion that the current paradigm allows for two courses of inference: divergent and convergent. It is remarkable that a measure recorded during a conscious task (attention task), which is performed simultaneously with an unconscious encoding task, predicted the outcome of unconscious encoding and inference as reflected in decisions taken $\sim 1$ min later at test.

Divergent thinking was suggested by slowed reactions on the attention task during periods, in which overlapping $\mathrm{B}-\mathrm{C}$ versus nonoverlapping $\mathrm{C}-\mathrm{D}$ pairs were being presented, because slowed reactions predicted more "don't fit" responses to episodically related A-C versus unrelated A-D words. Reactions in the attention task during periods where overlapping versus nonoverlapping pairs were being presented might have been slowed because divergent thinkers noticed a conflict between the retrieved $\mathrm{A}-\mathrm{B}$ pairs und the currently processed $\mathrm{B}-\mathrm{C}$ pairs. This might have given rise to puzzlement and distraction. A style of convergent thinking was suggested by speeded reactions to overlapping $\mathrm{B}-\mathrm{C}$ versus nonoverlapping $\mathrm{C}-\mathrm{D}$ pairs that predicted a larger number of "fit" responses to episodically related A-C versus unrelated A-D words. Speeded reactions during the encoding of overlapping versus nonoverlapping pairs in convergent thinkers may result from agreeing analyses of retrieved $\mathrm{A}-\mathrm{B}$ and currently processed $\mathrm{B}-\mathrm{C}$ pairs and from a facilitated processing of repeated $B$ words in B-C pairs. Although the facilitated processing of repeated $\mathrm{B}$ words might have been at play in divergent thinkers as well, it must have been overridden by the slowing effect of conflict perception.

In the whole group of participants, neither the difference in reaction times on the attention task (B-C: mean, $642 \mathrm{~ms}$; SD, $68 \mathrm{~ms}$; C-D: mean, $641 \mathrm{~ms}$; SD, $67 \mathrm{~ms}$; $\left.t_{(29)}=0.35, p=0.729\right)$ nor the difference in the number of "fit" responses (A-C: mean, 6.63; SD, 1.77; A-D: mean, 6.83; $\left.\mathrm{SD}, 1.56 ; t_{(29)}=-0.42, p=0.592\right) \mathrm{di}-$ verged from zero.

As reported above, all participants exhibited evidence of successful relational integration, as evidenced by their longer reaction times at test when judging episodically related versus unrelated words. We now ask whether this measure of successful relational integration is related to participants' style of inference (convergent vs divergent). Successful relational integration (difference in $\mathrm{RT}$ in $\mathrm{A}-\mathrm{C}$ vs

A-D retrieval pairs) was correlated neither with the difference in reaction times on the attention task $(r=0.125, p=0.511)$ nor with the difference in the number of "fit" responses $(r=$ $-0.194, p=0.305)$. Hence, successful relational integration

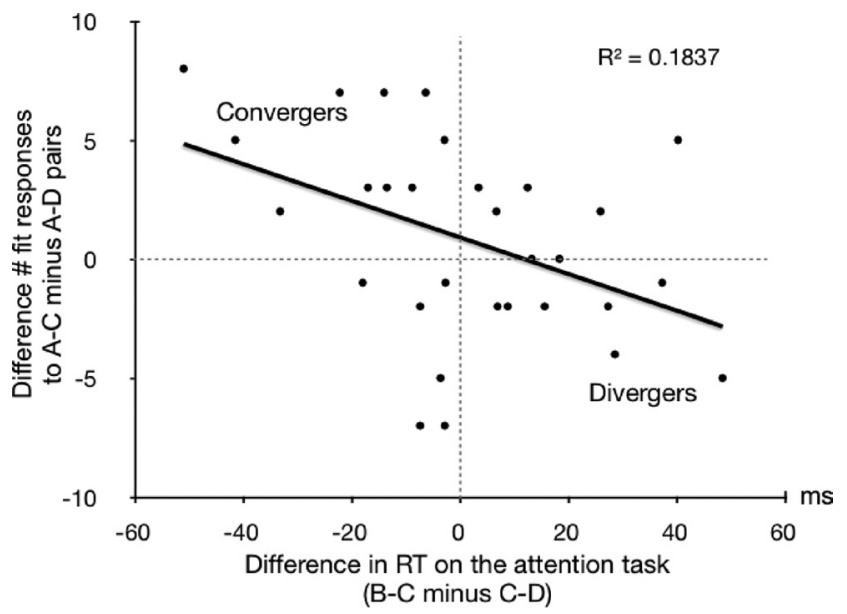

Figure 3. Behavioral results. The difference in RT on the attention task during blocks of $B-C$ presentations (experimental condition) versus blocks of $C-D$ presentations (control condition) predicted the difference in the number of "fit" responses to A-C pairs (experimental condition) versus A-D pairs (control condition). Top left quadrant, Typical pattern of participants with a convergent style of inference: briefer reaction times to $B-C$ pairs than C-D pairs at encoding and more "fit" answers to A-C than A-D pairs at test. Bottom right quadrant, Typical pattern of participants with a divergent style of inference: longer reaction times to B-C pairs than C-D pairs at encoding and less "fit" answers (or more "don't fit" answers) to A-C than A-D pairs at test.

\section{A Conjunction of encoding contrasts (B-C > C-D)}

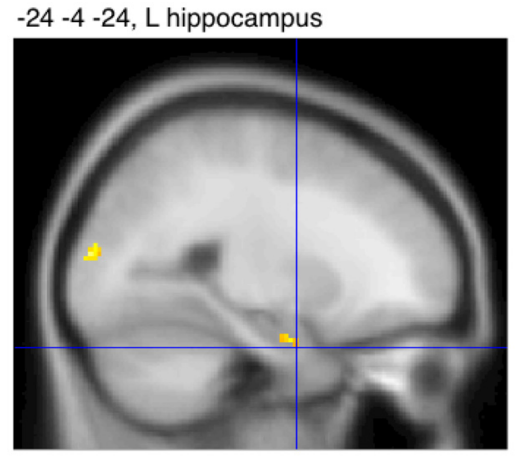

$20-446$, R parahippocampal cortex

B Conjunction of retrieval contrasts $(A-C>A-D)$

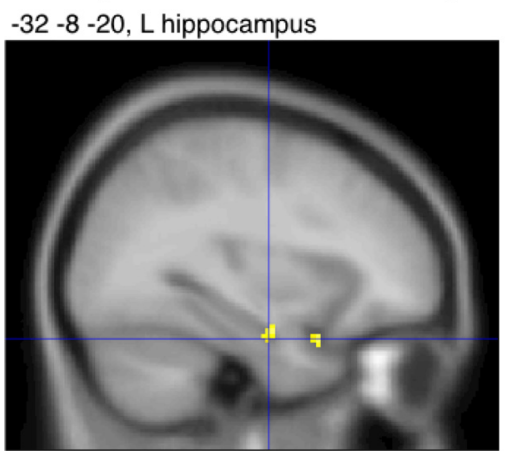

$36-6-16$, R hippocampus

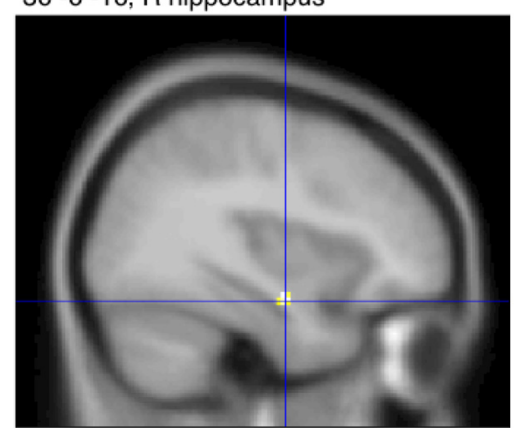

Figure 4. Common brain activation in participants with a divergent or convergent style of inference. $\boldsymbol{A}$, Results in the medial temporal lobe of a conjunction analysis performed on the encoding contrasts $(B-C>C-D)$ of convergent and divergent thinkers. $B$, Results in the medial temporal lobe of a conjunction analysis performed on the retrieval contrasts ( $A-C>A-D)$ of convergent and divergent thinkers. $A$, $B$, Commonly activated regions are depicted in yellow and reach significance at a height threshold of $p=0.001$ (uncorrected) and an extent threshold of 0 voxel. These fMRI results are presented on sagittal sections of a T1-weighted MNI template of SPM. L, Left; R, right.

was not predictive of the style of inference (convergent vs divergent).

To examine whether there was a systematic association of the two versions of stimulus lists (initial and counterbalanced list) 
with the group of convergent thinkers and the group of divergent thinkers, we split the sample into a subsample of convergent thinkers and a subsample of divergent thinkers. Participants with a difference in the number of "fit" responses between the experimental and control condition larger or smaller than zero were assigned to the group of convergent $(N=15)$ or divergent $(N=$ 15) thinkers, respectively. There was no systematic association of the two versions of stimulus lists with the two groups (Fisher's exact test: $p=0.466$, two-tailed). Furthermore, an ANOVA including the within-subjects factor Test Condition (experimental, control), the two between-subjects factors Group (convergent, divergent thinkers) and Stimulus List (List 1, List 2), and the dependent variable number of "fit" responses, revealed that both the interaction of Test Condition with Stimulus List $\left(F_{(1,26)}=0.283, p=\right.$ $0.599)$ and the interaction of Test Condition $\times$ Stimulus List $\times$ Group were nonsignificant $\left(F_{(1,26)}=0.171, p=0.682\right)$. But, as expected, the interaction of Group $\times$ Test Condition was significant $\left(F_{(1,26)}=47.902, p<10^{-7}\right)$. Hence, the pattern of "fit" responses that convergent and divergent thinkers gave in the two conditions was not influenced by stimulus lists.

\section{Common brain activation in participants with a divergent and convergent style of inference}

Conjunction analyses (Price and Friston, 1997) of the BOLD signal contrasts of convergent and divergent thinkers were computed to reveal brain regions commonly activated during encoding and retrieval. For encoding, we computed the conjunction of the contrast between the processing of overlapping subliminal B-C pairs versus nonoverlapping subliminal C-D pairs. For retrieval, we computed the conjunction of the contrast between the processing of episodically related A-C pairs versus unrelated A-D pairs.

Convergent and divergent thinkers commonly activated the left anterior hippocampus during the encoding of overlapping $\mathrm{B}-\mathrm{C}$ versus nonoverlapping C-D pairs (Fig. 4A, Table 1). This result is remarkable because the hippocampal activity difference might have been inversed due to a greater encoding requirement in the control than the experimental condition: $\mathrm{C}-\mathrm{D}$ pairs displayed in the control condition contained two new words, while $\mathrm{B}-\mathrm{C}$ pairs displayed in the experimental condition contained only one new word. Despite less stimulus novelty, B-C pairs challenged the left hippocampus more than $\mathrm{C}-\mathrm{D}$ pairs, which may have at least two reasons: (1) previously encoded A-B pairs were reactivated upon cueing with the word $\mathrm{B}$ contained in $\mathrm{B}-\mathrm{C}$ pairs, and (2) integrated representations of $\mathrm{A}-\mathrm{B}$ and $\mathrm{B}-\mathrm{C}$ pairs were established (Shohamy and Wagner, 2008). As reported above, the RT recorded during encoding spoke for the presence of inferential thinking at the time of $\mathrm{B}-\mathrm{C}$ presentations, which necessitates an unconscious cued recall of $\mathrm{A}-\mathrm{B}$ pairs and an unconscious integration of A-B with B-C pairs. Concomitant activity increases in the right parahippocampal cortex (Fig. 4A, Table 1), which has a role in the processing of contextual (both spatial and nonspatial) associations (Bar et al., 2008), suggest that words were contextually associated. Additional activity increases within bilateral areas of the superior temporal gyrus and areas of the right middle temporal gyrus (Table 1) suggest that additional semantic operations (Patterson et al., 2007; Binder et al., 2009) were required in the experimental versus the control condition. These additional semantic operations likely accompanied the recovery of concepts of A words and the integration of concepts of $\mathrm{A}, \mathrm{B}$, and $\mathrm{C}$ words as well as inferential thinking (independently of the direction of inference). The reason why primarily right rather than left lateral temporal activity increases emerged in this
Table 1. Common brain activation in participants with a divergent and convergent style of inference

\begin{tabular}{|c|c|c|c|c|c|c|c|c|}
\hline \multirow[b]{2}{*}{ Brain region } & \multirow[b]{2}{*}{ BA } & \multirow[b]{2}{*}{ Side } & \multicolumn{3}{|c|}{ MNI coordinates } & \multirow[b]{2}{*}{ K } & \multirow[b]{2}{*}{$t$} & \multirow[b]{2}{*}{$z$} \\
\hline & & & $x$ & $y$ & $z$ & & & \\
\hline \multicolumn{9}{|l|}{ Encoding } \\
\hline \multicolumn{9}{|l|}{$B-C>C-D$} \\
\hline Hippocampus & & L & -24 & -4 & -24 & 14 & 2.46 & 3.70 \\
\hline Parahippocampal cortex & 30 & $\mathrm{R}$ & 20 & -44 & 6 & 21 & 2.88 & 4.18 \\
\hline $\begin{array}{l}\text { Middle and superior } \\
\text { temporal gyrus }\end{array}$ & $21 / 22$ & $\mathrm{R}$ & 64 & -16 & -2 & 99 & 3.67 & 5.01 \\
\hline Middle temporal gyrus & 39 & $\mathrm{R}$ & 38 & -72 & 12 & 51 & 3.19 & 4.52 \\
\hline Superior ten & 22 & L & -58 & 0 & -2 & 35 & 2.91 & 4.21 \\
\hline Middle cingulate gyrus & 32 & L & -6 & -2 & 42 & 32 & 2.69 & 3.96 \\
\hline $\begin{array}{l}\text { Precentral gyrus, superior } \\
\text { frontal gyrus }\end{array}$ & $4 / 6$ & $\mathrm{R}$ & 28 & -12 & 72 & 76 & 3.18 & 4.50 \\
\hline Middle occipital gyrus & 18 & L & -24 & -92 & 14 & 47 & 2.96 & 4.26 \\
\hline Middle occipital gyrus & 19 & $\mathrm{R}$ & 30 & -82 & 10 & 32 & 2.96 & 4.27 \\
\hline$C-D>B-C$ & N.S. & N.S. & N.S. & N.S. & N.S. & N.S. & N.S. & N.S. \\
\hline \multicolumn{9}{|l|}{ Retrieval } \\
\hline \multicolumn{9}{|l|}{$A-C>A-D$} \\
\hline Hippocampus & & L & -32 & -8 & -20 & 8 & 2.42 & 3.65 \\
\hline Hippocampus & & $\mathrm{R}$ & 36 & -6 & -16 & 27 & 2.97 & 4.22 \\
\hline Anterior cingulate gyrus & 32 & L & -10 & 20 & 38 & 27 & 2.89 & 4.19 \\
\hline Anterior cingulate gyrus & 24 & $L / R$ & 2 & 22 & 24 & 25 & 2.74 & 4.02 \\
\hline \multicolumn{9}{|l|}{$A-D>A-C$} \\
\hline Hippocampus & & L & -22 & -30 & -6 & 12 & 2.33 & 3.56 \\
\hline Fusiform gyrus & 20 & $\mathrm{R}$ & 34 & -36 & -20 & 56 & 2.8 & 4.09 \\
\hline Superior frontal gyrus & 10 & $\mathrm{R}$ & 20 & 52 & 20 & 23 & 2.86 & 4.16 \\
\hline Superior parietal lobule & 7 & L & -16 & -74 & 36 & 75 & 3.11 & 4.43 \\
\hline
\end{tabular}

Height threshold $p=0.001$; extent threshold $=0$ voxels for the medial temporal lobe and 20 voxels for the rest of the brain. MNI coordinates stand for the peak voxel within significantly activated cluster of voxels. $k$, Extent of significant cluster (number of voxels); BA, Brodmann area; L, left; R, right; N.S., no significant results.

contrast might be the integrative style of encoding and inferential thinking. In fact, right hemisphere homologues of language areas have been found to support the achievement of coherence in language processing (St George et al., 1999; Jung-Beeman, 2005) and the making of inferences during story comprehension (JungBeeman, 2005; Virtue et al., 2006). Further activity increases in the left and right middle occipital gyrus (Table 1) may indicate more mental visuospatial processing (Viard et al., 2011) in the experimental condition $(\mathrm{B}-\mathrm{C})$, where $\mathrm{A}-\mathrm{B}$ pairs were reactivated and integrated with $\mathrm{B}-\mathrm{C}$ pairs, than the control condition, where new pairs were encoded.

The conjunction of the reverse encoding contrasts yielded no significant results, indicating that neural computations in the control condition did not exceed those in the experimental condition.

The conjunction of the retrieval contrasts, which compared the processing of episodically related A-C pairs versus unrelated A-D pairs, revealed activity increases in the left and right anterior hippocampus near the above-reported encoding-related activation focus (Fig. 4B, Table 1). Hence, the recovery of A-B and B-C relations upon confrontation with $\mathrm{A}-\mathrm{C}$, and the potential additional recovery of earlier (during encoding) formed mental representations of $\mathrm{A}-\mathrm{B}-\mathrm{C}$ relations, engaged the anterior hippocampus bilaterally. Further activity foci were located in the anterior cingulate gyrus (Table 1), a region that supports the retrieval from episodic memory (Cabeza and Nyberg, 2000) and-more generally-retrieval from declarative memory (Burianova et al., 2010).

The conjunction of the reverse retrieval contrasts also yielded significant results (Table 1). An area in the left posterior hippocampus exhibited more activity when unrelated A-D pairs versus episodically related $\mathrm{A}-\mathrm{C}$ pairs were displayed. The inspection of the beta weights of each condition (A-C, A-D, baseline) in the 

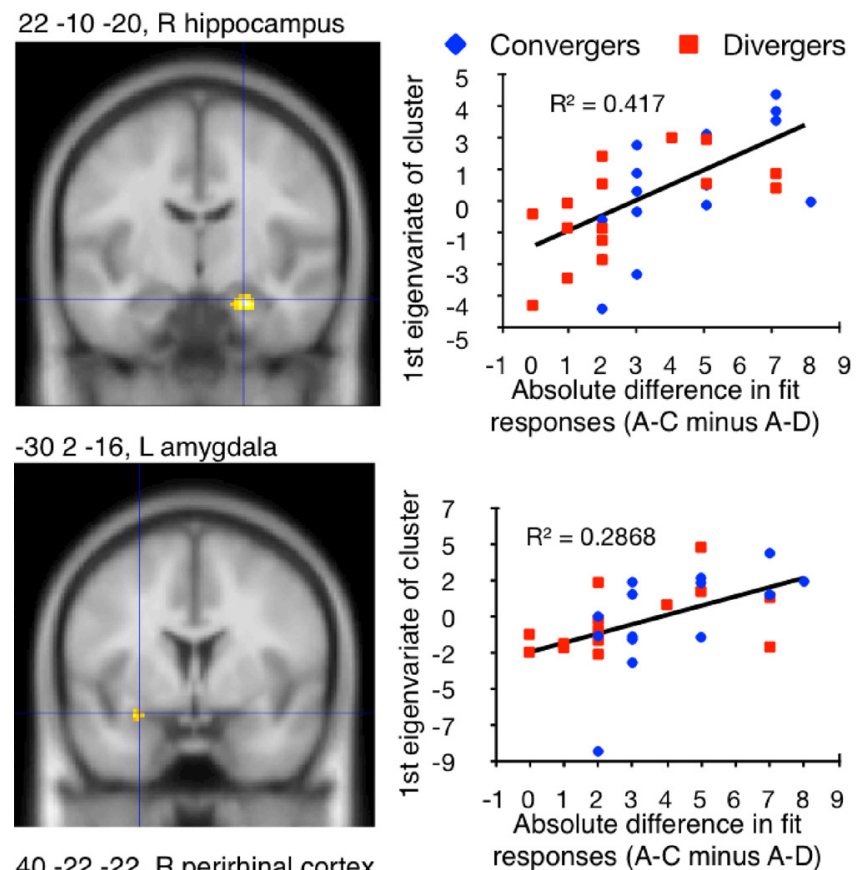

$40-22-22$, R perirhinal cortex
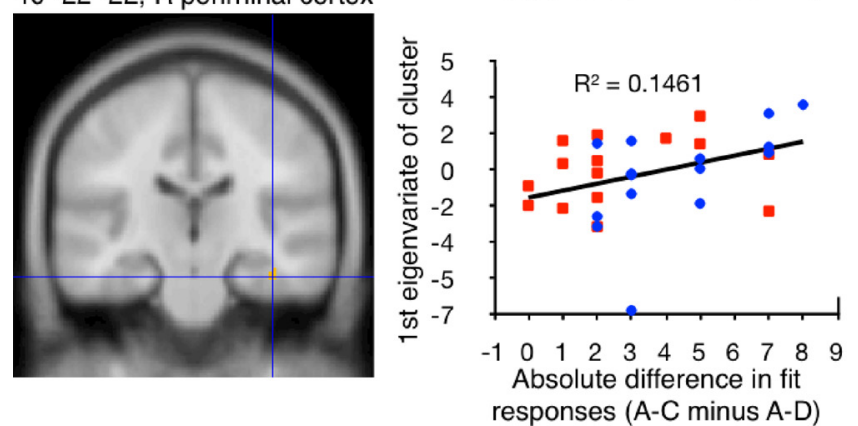

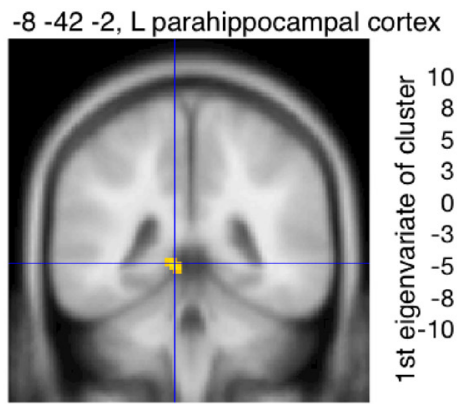

32 -36 -8, R parahippocampal cortex
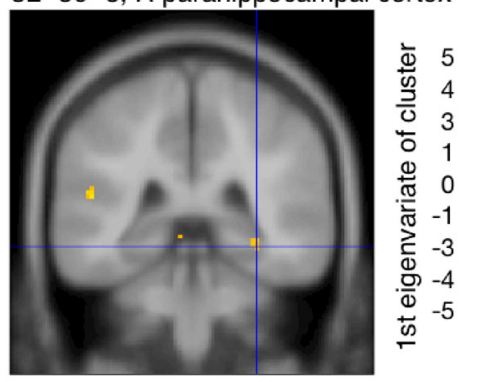

$-62-3010, \mathrm{~L}$ superior temporal gyrus

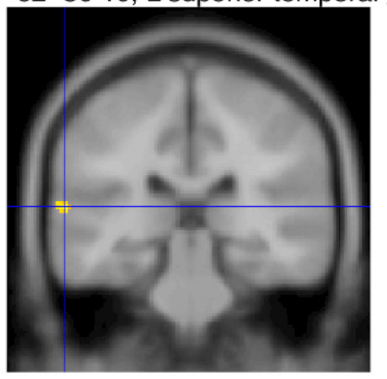


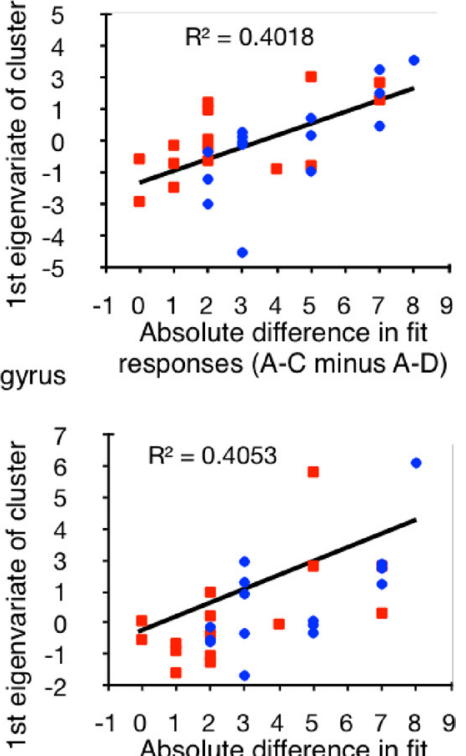

Figure 5. Encoding activity predicted performance at test. Results of the correlation between the encoding contrast (B-C $>C-D)$ and the absolute difference in the number of "fit" responses given to A-C (experimental condition) versus A-D pairs (control condition) at test. Because we used absolute difference values in this correlation, high test scores represent a good performance in both convergent and divergent thinkers. Significant results of the correlation are depicted in yellow and marked by a blue crosshair on coronal sections of a T1-weighted MNI template of SPM. These results reached significance at a height threshold of $p=0.001$ (uncorrected) and an extent threshold of 0 voxel for medial temporal lobe areas and 20 voxels for all other brain regions. Significant correlations are also presented in scatter plots, where blue symbols stand for convergent thinkers and red symbols for divergent thinkers. The first eigenvariate of a significant cluster was extracted and depicted in arbitrary units on the $y$-axes of the scatter plots. L, Left; R, right.

peak voxel of this cluster revealed that this difference was due to a deactivation in the $\mathrm{A}-\mathrm{C}$ versus the $\mathrm{A}-\mathrm{D}$ and baseline condition. A deactivation or enhanced deactivation during the inspection of $\mathrm{A}-\mathrm{C}$ versus $\mathrm{A}-\mathrm{D}$ and baseline stimuli was also the reason for further effects located in the left superior parietal lobule, the right superior frontal gyrus, and the right fusiform gyrus.

\section{Encoding activity predicted performance at test}

We correlated the encoding contrast $(\mathrm{B}-\mathrm{C}>\mathrm{C}-\mathrm{D})$ and the retrieval contrast $(\mathrm{A}-\mathrm{C}>\mathrm{A}-\mathrm{D})$ with the absolute difference in the number of "fit" responses to A-C pairs versus A-D pairs. The use of absolute difference values brings convergent and divergent thinkers on a common scale that ranges from zero to 16 .

The positive correlation of the encoding contrast with performance at test yielded significant results in areas that also provided significant results in the above-reported conjunction of encoding contrasts. These areas are the anterior part of hippocampus (right side), parahippocampal cortex (bilaterally), and the superior temporal gyrus (left side). Further significant correlations appeared in the right perirhinal cortex and left amygdala (Fig. 5). Those participants who activated these temporal areas to a large extent during the presentation of $\mathrm{B}-\mathrm{C}$ versus $\mathrm{C}-\mathrm{D}$ pairs yielded a larger performance score at test. The cognitive processes that may have driven the correlations in these areas likely consisted of the mental reactivation of previously encoded semantic relations between $\mathrm{A}-\mathrm{B}$ pairs and their integration with the currently encoded $\mathrm{B}-\mathrm{C}$ pairs in the experimental condition. The better participants succeeded in semantically integrating the two pairs at encoding, the better they performed at test. Because both participants with a convergent and participants with a divergent style of inference contributed to these correlations (Fig. 5), we assume that the direction of inference-convergent versus divergent- did not determine performance at test. We would like to point out that the above correlations show that neuroimaging data recorded during subliminal encoding, which was recorded $\sim 1$ min before test, predicted decisions taken at test. This suggests that unconscious encoding processes can durably affect apparently deliberate choices in new situations.

The inverse correlation of the encoding contrast with performance at test yielded no significant results. This means that neither activity-decreases in the experimental versus the control condition nor activity-increases in the control versus the experi- 
Table 2. Differences in brain activation between participants with a divergent and convergent style of inference

\begin{tabular}{|c|c|c|c|c|c|c|c|c|}
\hline \multirow[b]{2}{*}{ Brain region } & \multirow[b]{2}{*}{ BA } & \multirow[b]{2}{*}{ Side } & \multicolumn{3}{|c|}{ MNI coordinates } & \multirow[b]{2}{*}{$k$} & \multirow[b]{2}{*}{$t$} & \multirow[b]{2}{*}{$z$} \\
\hline & & & $x$ & $y$ & $z$ & & & \\
\hline \multicolumn{9}{|l|}{ Convergent thinkers } \\
\hline \multicolumn{9}{|l|}{$>$ divergent thinkers } \\
\hline Posterior cingulate gyrus & 23 & $\mathrm{~L}$ & -16 & -42 & 24 & 75 & 4.29 & 3.71 \\
\hline \multicolumn{9}{|l|}{ Retrieval $(A-C>A-D)$} \\
\hline Parahippocampal cortex & 30 & $\mathrm{~L}$ & -12 & -42 & 2 & 36 & 4.79 & 4.04 \\
\hline Anterior cingulate gyrus & 32 & $\mathrm{R}$ & 12 & 4 & 46 & 29 & 4.65 & 3.95 \\
\hline Middle occipital gyrus & 19 & $\mathrm{R}$ & 42 & -84 & 8 & 34 & 6.14 & 4.81 \\
\hline \multicolumn{9}{|l|}{ Divergent thinkers } \\
\hline \multicolumn{9}{|l|}{$\begin{array}{l}>\text { convergent thinkers } \\
\text { Encoding }(B-C>C-D)\end{array}$} \\
\hline $\begin{array}{l}\text { Medial portion of superior } \\
\text { frontal gyrus }\end{array}$ & 8 & $\mathrm{~L} / \mathrm{R}$ & 0 & 34 & 54 & 21 & 4.13 & 3.6 \\
\hline Retrieval $(A-C>A-D)$ & Noactivations & & & & & & & \\
\hline
\end{tabular}

Height threshold $p=0.001$; extent threshold $=0$ voxels for the medial temporal lobe and 20 voxels for the rest of the brain. MNI coordinates stand for the peak voxel within significantly activated cluster of voxels. $k$, Extent of significant cluster (number of voxels); BA, Brodmann area; L, left; $R$, right.

mental condition related linearly to performance at test. Equally, neither the positive nor the inverse correlation of the retrieval contrast with test performance yielded significant results. Hence, brain activation during the encoding of overlapping pairs was predictive of test performance, while brain activity recorded during test performance was not. A possible reason for this is that an essential part of relational integration and convergent/divergent inference is performed during encoding rather than test. Related blood oxygenation changes might therefore predict performance at test better than blood oxygenation changes recorded in the test situation itself.

\section{Differences in brain activation between participants with a divergent and convergent style of inference}

The above results suggest that both participants with a convergent and participants with a divergent style of inference are capable of unconscious relational integration using similar neural networks. Here, we explored how differences in the two cognitive styles map onto differences in brain activation. To this aim, we computed comparisons between the two groups' encoding contrasts and retrieval contrasts.

A convergent style of inference at the time of encoding was associated with increases of activity in a large area of the posterior cingulate gyrus (Table 2). The posterior cingulate gyrus is a multimodal association area that integrates retrieved and newly presented information (Ryan et al., 2001; Hunkin et al., 2002). It is possible that convergent thinkers invested more neural resources into the integration of reactivated $\mathrm{A}-\mathrm{B}$ words and currently encoded B-C words. Convergent versus divergent thinkers also exhibited activity increases at the time of retrieval. These activity increases were located in the right anterior cingulate gyrus, left parahippocampal cortex, and right middle occipital gyrus (Table 2 ). Because the anterior cingulate gyrus is prominently engaged in the retrieval from episodic memory (Cabeza and Nyberg, 2000) and-more generally-retrieval from declarative memory (Burianova et al., 2010), convergent thinkers might have recruited more neurons to recover learned relations. That this recovery concerned verbal-conceptual information (Binder et al., 2009), in particular associations (Bar et al., 2008), is suggested by the activity increase in left parahippocampal cortex. Convergers' versus divergers' activity increases in the right middle occipital gyrus point to a greater recruitment of neurons in a region that is known to support visuospatial processing, which promotes the retrieval of episodes experienced in the past (Viard et al., 2011). Although the above-reported conjunction analysis showed that convergent and divergent thinkers activated a large common encoding and retrieval network, these results indicate that convergent thinkers invested additional neural resources compared with divergent thinkers into associative encoding and retrieval. When we compared the two groups' test performances using the above-introduced absolute difference in the number of "fit" responses to A-C pairs versus A-D pairs, convergent thinkers exhibited a marginally better performance than divergent thinkers (converger: mean, 4.33; SD, 2.09; diverger: mean, 2.73; SD, 2.31; $\left.t_{(28)}=-1.99, p=0.057\right)$. Hence, a convergent thinking mode benefitted relational integration.

A divergent versus convergent style of inference was associated with increased activity in the medial portion of the superior frontal gyrus at the time of encoding, but no differential activity was found at the time of retrieval (Table 2). The medial portion of the superior frontal gyrus has been found activated during the monitoring of conflicts (Ridderinkhof et al., 2004), and in particular when evaluating sentences that were conflicting and ambiguous (Ye and Zhou, 2009). In the present study, divergent thinkers may have noticed conflicts between previously encoded $\mathrm{A}-\mathrm{B}$ and currently processed $\mathrm{B}-\mathrm{C}$ pairs.

\section{Postexperimental assessment of awareness}

To make a claim of unconscious processing, it is vital to exclude the possibility of a conscious contamination of subliminal word encoding. At the end of the experiment, participants underwent a structured interview aimed at revealing whether they had suspected subliminal stimuli. None of participants reported to have suspected or even perceived subliminal stimuli or fragments thereof. Finally, we conducted a forced-choice test to objectify potential consciousness of word perception. It is standard procedure to contrast performance in so-called "direct" tests that tap primarily conscious stimulus perception with the performance in "indirect" tests that tap primarily unconscious stimulus perception (Cheesman and Merikle, 1984; Snodgrass and Shevrin, 2006). A claim of unconscious perception can be made if the indirect test, but not the direct test, yields significant effects of stimulus perception (Cheesman and Merikle, 1984). Participants' forcedchoice behavior in the direct test revealed chance performance (correct: mean, 14.6; SD, 1.63; incorrect: mean, 15.4; SD, 1.63; $t_{(29)}=-1.343, p=0.380$, one-tailed). Thus, participants' subjective reports and their forced-choice behavior indicated that subliminal words were not consciously perceived.

We also computed a regression analysis (Greenwald et al., 1995), in which the performance in the awareness test was the predictor of the RT difference between $\mathrm{A}-\mathrm{C}$ and $\mathrm{A}-\mathrm{D}$ pairs in the experiment. This analysis revealed a significant intercept ( $y$-axis intercept $\left.=64.70 \mathrm{~ms}, t_{(29)}=2.571, p=0.016\right)$, while the slope was not significant $\left(\mathrm{B}=0.085, t_{(29)}=0.453, p=0.654\right)$. This result indicates that unconscious relational integration as measured in the experiment was not correlated with stimulus discriminability as assessed in the awareness test. The significant intercept suggests that unconscious processing persists, even if potential contributions of conscious stimulus processing are regressed out (Greenwald et al., 1995).

\section{Discussion}

The behavioral results indicate that participants had encoded semantic relations between words within and across subliminal episodes. The successful integration of two overlapping word 
pairs speaks for a rapid mode of encoding and a durable retention of the formed associations because subliminal episodes were unique (no repetitions) and presented $66 \mathrm{~s}$ away from their corresponding subliminal episode. The behavioral and imaging data suggest that relational integration and inferential thinking started at the time of encoding and were resumed and perhaps completed at the time of test.

Half of participants (divergent thinkers) seem to have considered a word's simultaneous association with two other words as conflicting and inferred that the two simultaneously associated words were semantically distant. The other half of participants (convergent thinkers) seemed to have accommodated the two associates with their common word in an agreeing way, inferring that the two associates were semantically near. Both directions of inference, convergent and divergent, are valid outcomes in the current paradigm because we did not manipulate the direction of inference experimentally. Convergent and divergent thinkers did not appear to differ much in terms of their ability for relational integration, as evidenced by the behavioral and imaging data (Figs. 3, 5; Table 2). Therefore, a divergent style of inference cannot be explained by a better item-context or item-item memory that would provide for a larger mnemonic basis for the perception of competition between A and C words (Provyn et al., 2007; Buchler et al., 2011). If anything, our data indicate that a convergent thinking mode benefits relational encoding and integration more than a divergent thinking mode because convergent thinkers invested additional neural resources into associative encoding/retrieval and exhibited a slightly better test performance.

Importantly, all relevant cognitive processes-encoding, retrieval, integration, and inference-were performed outside participants' conscious awareness. Despite participants' unawareness of encoding, integrating, and retrieving overlapping word pairs, they exhibited large effects in medial temporal areas, in particular within the anterior hippocampus. Notably, anterior hippocampal activity recorded at the time of encoding predicted the outcome of relatedness decisions taken $\sim 1 \mathrm{~min}$ later at test. These findings point to a role of the anterior hippocampus (and other medial temporal structures) in unconscious relational integration. Because the direction of inference-convergent versus divergent- did not modulate hippocampal activity, we assume that hippocampal encoding, retrieval, and integration processes provided an information base for neural computations in other brain areas to afford inference. The inferential thinking mode in turn might then have affected relational encoding/retrieval by modulating cognitive and neural computations outside the hippocampus.

These results corroborate previous evidence of a hippocampal role in the rapid relational encoding of subliminal stimulus pairs and their long-term retention (Henke et al., 2003a,b; Degonda et al., 2005). In addition, these results expand the scope of computations believed possible without consciousness and assisted by the hippocampus. Unconscious relational memories were reactivated when prompted by subliminal retrieval cues (B words contained in B-C pairs), integrated over subliminal episodes, and reactivated upon presentation of a new configuration of encoding words. The fact that subliminal words were effective retrieval cues shows that even the sparse and brief neural activity elicited by a subliminal cue is conducive to the reactivation of a weak memory trace formed earlier during a subliminal event. Most importantly, the present results show that associations formed in the course of distinct subliminal events may be integrated. This extends previous evidence of subliminal encoding and retrieval of individual associations (Henke et al., 2003a,b; Degonda et al., 2005; Duss et al., 2011). Finally, the retrieval context in the cur- rent experiment called for a flexible retrieval of two intertwined memory traces, whereas the retrieval cues provided in the earlier studies helped to reactivate only one association at a time (Henke et al., 2003a,b; Degonda et al., 2005; Duss et al., 2011).

The first evidence that true inference may proceed unconsciously was provided by Greene and colleagues (Greene et al., 2001, 2006; Leo and Greene, 2008). The participants in their studies had consciously encoded suprathreshold premise pairs. The participants' performance at test indicated successful inference even if they reported to be unaware of the rules that governed their decisions (Greene et al., 2001, 2006; Leo and Greene, 2008). The current findings underscore these results and extend them by showing that awareness is not even required for the encoding of premise pairs. Greene and colleagues (Greene et al., 2001, 2006; Leo and Greene, 2008), as well as other investigators of unconscious inference (Smith and Squire, 2005; Libben and Titone, 2008; Moses et al., 2010), presented the encoding and test material suprathreshold, i.e., for conscious inspection. Awareness of the interrelatedness between encoding items was assessed following the experiment using a questionnaire. Although this procedure corresponds to common practice, we believe that consciousness of the task structure is more reliably excluded if the encoding material is presented invisibly to participants.

Our fMRI data indicate that the hippocampus contributed to the integration of memories of word pairs both at the time of encoding, when B-C pairs were presented, and again at the time of test. Reaction times recorded on the attention task, which participants performed during the subliminal presentations, indicated that participants made already convergent or divergent inferences when they were confronted with overlapping subliminal word pairs. While this finding speaks for an early time point of relational integration and implicates a facilitated processing of episodically related words at test (Shohamy and Wagner, 2008), reaction times at test were in fact longer for episodically related than unrelated word pairs. We assume that relational integration was initiated at the time of encoding and resumed and completed at the time of test, which extended reaction times on the group level. Nevertheless, some participants displayed faster reactions to episodically related versus unrelated test pairs suggesting that these participants proceeded further with relational integration at the time of encoding than the rest of our participants. Accordingly, more efficient processing of episodically related words was predicted by increased hippocampal activity at the time of encoding. It should be noted that a previous behavioral study with a similar design yielded faster reactions to A-C than A-D test pairs also on the group level (Reber and Henke, 2012). Because those participants were examined in a completely calm environment (no MR noise) and were well rested, they may have been able to fully integrate overlapping word pairs at encoding, which saved them processing time at test. The current participants, however, performed this experiment as the last in a series of fMRI experiments that day and were exposed to scanner noise for a long time. Together, we assume that relational integration and inference may not proceed in an all-or-none fashion, but may be distributed in time, occurring during encoding (Shohamy and Wagner, 2008), between study and test (Ellenbogen et al., 2007), or at test (Dusek and Eichenbaum, 1997; Heckers et al., 2004; Preston et al., 2004).

The finding of a hippocampal involvement in unconscious relational integration and inference is at odds with classic notions of human long-term memory that segregate memory systems according to consciousness of encoding and retrieval (Tulving, 2002; Squire, 2004; Smith et al., 2006; Squire and Wixted, 2011). 
The medial temporal lobe, and in particular the hippocampus, is considered part of a memory system that subserves only the conscious formation and retrieval of episodic or declarative memories. Accordingly, only conscious memories are thought to be flexibly integrated and expressed (Reber et al., 1996; Smith and Squire, 2005). However, these classic notions have been questioned by the finding of implicit inference (Greene et al., 2001, 2006; Leo and Greene, 2008), by the finding of an implicit expression of hippocampus-dependent memory indexed by eye movements (Hannula and Ranganath, 2009; Voss et al., 2011), and by the finding of unconscious association formation and retrieval with concurrent hippocampal activation (Henke et al., 2003a,b; Degonda et al., 2005). Our current findings extend these previous findings by showing that the exclusion of conscious awareness of encoding and retrieval does not abolish rapid relational integration or long-term storage or the flexible expression of memories in new contexts or task-related hippocampal computation.

Our evidence supports recent accounts of medial temporal lobe functions that emphasize the computational capabilities of medial temporal structures and the nature of the information that is processed and stored in medial temporal regions (Eichenbaum et al., 1999, 2007; Ryan et al., 2000; Brown and Aggleton, 2001; Bussey and Saksida, 2005; Moses and Ryan, 2006; Mayes et al., 2007; Henke, 2010; Ranganath, 2010). These processing-based viewpoints advance our understanding because they reveal basic computational principles of medial temporal structures that come into effect in various cognitive situations. These basic computational principles may help linking traditionally separate fields of research, such as long- and short-term memory (Ranganath, 2010); memory and perception (Bussey and Saksida, 2005); and memory, spatial navigation, future planning, and inference (Eichenbaum et al., 1999). More specifically, our evidence supports the relational memory theory that does not consider consciousness a necessary condition for hippocampal processing (Ryan et al., 2000; Moses and Ryan, 2006). According to the relational memory theory (Cohen and Eichenbaum, 1993), the hippocampus encodes a memory space in which the relationships between the various aspects of experienced events are associated in a flexible way that allows for inference and memory-based predictions. Our evidence also supports a model that distinguishes memory systems on grounds of their computational capabilities (Henke, 2010). Whenever rapid and flexible relation formation and retrieval are required, hippocampal processing is called for, independently of consciousness of the ongoing memory processes.

\section{References}

Bar M, AminoffE, Schacter DL (2008) Scenes unseen: the parahippocampal cortex intrinsically subserves contextual associations, not scenes or places per se. J Neurosci 28:8539-8544.

Biemann C, Bordag S, Heyer G, Quasthoff U, Wolf C (2004) Languageindependent methods for compiling monolingual lexical data. In: Computational linguistics and intelligent text processing (Lecture notes in computer science, vol. 2945) (Gelbukh A, ed), pp 217-228. Berlin/Heidelberg: Springer.

Binder JR, Desai RH, Graves WW, Conant LL (2009) Where is the semantic system? A critical review and meta-analysis of 120 functional neuroimaging studies. Cereb Cortex 19:2767-2796.

Brown MW, Aggleton JP (2001) Recognition memory: what are the roles of the perirhinal cortex and hippocampus? Nat Rev Neurosci 2:51-61.

Buchler NG, Faunce P, Light LL, Gottfredson N, Reder LM (2011) Effects of repetition on associative recognition in young and older adults: item and associative strengthening. Psychol Aging 26:111-126.

Bunsey M, Eichenbaum H (1996) Conservation of hippocampal memory function in rats and humans. Nature 379:255-257.
Burianova H, McIntosh AR, Grady CL (2010) A common functional brain network for autobiographical, episodic, and semantic memory retrieval. Neuroimage 49:865-874.

Bussey TJ, Saksida LM (2005) Object memory and perception in the medial temporal lobe: an alternative approach. Curr Opin Neurobiol 15:730-737.

Cabeza R, Nyberg L (2000) Imaging cognition. II. An empirical review of 275 PET and fMRI studies. J Cogn Neurosci 12:1-47.

Cheesman J, Merikle PM (1984) Priming without awareness. Percept Psychophys 36:387-395.

Cohen NJ, Eichenbaum H (1993) Memory, amnesia and the hippocampal system. Cambridge, MA: MIT.

Cook NJ (1986) The brain code. London: Methuen.

Degonda N, Mondadori CR, Bosshardt S, Schmidt CF, Boesiger P, Nitsch RM, Hock C, Henke K (2005) Implicit associative learning engages the hippocampus and interacts with explicit associative learning. Neuron 46:505-520.

Dusek JA, Eichenbaum H (1997) The hippocampus and memory for orderly stimulus relations. Proc Natl Acad Sci U S A 94:7109-7114.

Duss SB, Oggier S, Reber TP, Henke K (2011) Formation of semantic associations between subliminally presented face-word pairs. Conscious Cogn 20:928-935.

Eichenbaum H, Dudchenko P, Wood E, Shapiro M, Tanila H (1999) The hippocampus, memory, and place cells: is it spatial memory or a memory space? Neuron 23:209-226.

Eichenbaum H, Yonelinas AP, Ranganath C (2007) The medial temporal lobe and recognition memory. Annu Rev Neurosci 30:123-152.

Ellenbogen JM, Hu PT, Payne JD, Titone D, Walker MP (2007) Human relational memory requires time and sleep. Proc Natl Acad Sci U S A 104:7723-7728.

Frank MJ, Rudy JW, O’Reilly RC (2003) Transitivity, flexibility, conjunctive representations, and the hippocampus. II. A computational analysis. Hippocampus 13:341-354.

Frank MJ, O'Reilly RC, Curran T (2006) When memory fails, intuition reigns: midazolam enhances implicit inference in humans. Psychol Sci 17:700-707.

Greene AJ, Spellman BA, Dusek JA, Eichenbaum HB, Levy WB (2001) Relational learning with and without awareness: transitive inference using nonverbal stimuli in humans. Mem Cognit 29:893-902.

Greene AJ, Gross WL, Elsinger CL, Rao SM (2006) An FMRI analysis of the human hippocampus: inference, context, and task awareness. J Cogn Neurosci 18:1156-1173.

Greenwald AG, Klinger MR, Schuh ES (1995) Activation by marginally perceptible ("subliminal") stimuli: dissociation of unconscious from conscious cognition. J Exp Psychol Gen 124:22-42.

Hannula DE, Ranganath C (2009) The eyes have it: hippocampal activity predicts expression of memory in eye movements. Neuron 63:592-599.

Heckers S, Zalesak M, Weiss AP, Ditman T, Titone D (2004) Hippocampal activation during transitive inference in humans. Hippocampus 14:153-162.

Henke K (2010) A model for memory systems based on processing modes rather than consciousness. Nat Rev Neurosci 11:523-532.

Henke K, Treyer V, Nagy ET, Kneifel S, Dürsteler M, Nitsch RM, Buck A (2003a) Active hippocampus during nonconscious memories. Conscious Cogn 12:31-48.

Henke K, Mondadori CR, Treyer V, Nitsch RM, Buck A, Hock C (2003b) Nonconscious formation and reactivation of semantic associations by way of the medial temporal lobe. Neuropsychologia 41:863-876.

Hunkin NM, Mayes AR, Gregory LJ, Nicholas AK, Nunn JA, Brammer MJ, Bullmore ET, Williams SC (2002) Novelty-related activation within the medial temporal lobes. Neuropsychologia 40:1456-1464.

Jung-Beeman M (2005) Bilateral brain processes for comprehending natural language. Trends Cogn Sci 9:512-518.

Leo PD, Greene AJ (2008) Is awareness necessary for true inference? Mem Cognit 36:1079-1086.

Libben M, Titone D (2008) The role of awareness and working memory in human transitive inference. Behav Processes 77:43-54.

Mayes A, Montaldi D, Migo E (2007) Associative memory and the medial temporal lobes. Trends Cogn Sci 11:126-135.

Moses SN, Ryan JD (2006) A comparison and evaluation of the predictions of relational and conjunctive accounts of hippocampal function. Hippocampus 16:43-65. 
Moses SN, Brown TM, Ryan JD, McIntosh AR (2010) Neural system interactions underlying human transitive inference. Hippocampus 20:894901.

Patterson K, Nestor PJ, Rogers TT (2007) Where do you know what you know? The representation of semantic knowledge in the human brain. Nat Rev Neurosci 8:976-987.

Preston AR, Shrager Y, Dudukovic NM, Gabrieli JD (2004) Hippocampal contribution to the novel use of relational information in declarative memory. Hippocampus 14:148-152.

Price CJ, Friston KJ (1997) Cognitive conjunction: a new approach to brain activation experiments. Neuroimage 5:261-270.

Provyn JP, Sliwinski MJ, Howard MW (2007) Effects of age on contextually mediated associations in paired associate learning. Psychol Aging 22:846-857.

Ranganath C (2010) A unified framework for the functional organization of the medial temporal lobes and the phenomenology of episodic memory. Hippocampus 20:1263-1290.

Reber PJ, Knowlton BJ, Squire LR (1996) Dissociable properties of memory systems: differences in the flexibility of declarative and nondeclarative knowledge. Behav Neurosci 110:861-871.

Reber TP, Henke K (2011) Rapid formation and flexible expression of memories of subliminal word pairs. Front Psychol 2:343.

Reber TP, Henke K (2012) Integrating unseen events over time. Conscious Cogn [Epub ahead of print]. http://dx.doi.org/10.1016/j.concog.2012.02.013.

Ridderinkhof KR, Ullsperger M, Crone EA, Nieuwenhuis S (2004) The role of the medial frontal cortex in cognitive control. Science 306:443-447.

Ryan JD, Althoff RR, Whitlow S, Cohen NJ (2000) Amnesia is a deficit in relational memory. Psychol Sci 11:454-461.

Ryan L, Nadel L, Keil K, Putnam K, Schnyer D, Trouard T, Moscovitch M (2001) Hippocampal complex and retrieval of recent and very remote autobiographical memories: evidence from functional magnetic resonance imaging in neurologically intact people. Hippocampus 11:707-714.

Schmidt CF, Degonda N, Luechinger R, Henke K, Boesiger P (2005) Sensitivity-encoded (SENSE) echo planar fMRI at $3 \mathrm{~T}$ in the medial temporal lobe. Neuroimage 25:625-641.
Shaywitz BA, Shaywitz SE, Pugh KR, Constable RT, Skudlarski P, Fulbright RK, Bronen RA, Fletcher JM, Shankweiler DP, Katz L (1995) Sex differences in the functional organization of the brain for language. Nature 373:607-609.

Shohamy D, Wagner AD (2008) Integrating memories in the human brain: hippocampal-midbrain encoding of overlapping events. Neuron 60 : 378-389.

Smith C, Squire LR (2005) Declarative memory, awareness, and transitive inference. J Neurosci 25:10138-10146.

Smith CN, Hopkins RO, Squire LR (2006) Experience-dependent eye movements, awareness, and hippocampus-dependent memory. J Neurosci 26:11304-11312.

Snodgrass M, Shevrin H (2006) Unconscious inhibition and facilitation at the objective detection threshold: replicable and qualitatively different unconscious perceptual effects. Cognition 101:43-79.

Squire LR (2004) Memory systems of the brain: a brief history and current perspective. Neurobiol Learn Mem 82:171-177.

Squire LR, Wixted JT (2011) The cognitive neuroscience of human memory since H.M. Annu Rev Neurosci 34:259-288.

St George M, Kutas M, Martinez A, Sereno MI (1999) Semantic integration in reading: engagement of the right hemisphere during discourse processing. Brain 122:1317-1325.

Tulving E (2002) Episodic memory: from mind to brain. Annu Rev Psychol 53:1-25.

Viard A, Chételat G, Lebreton K, Desgranges B, Landeau B, de La Sayette V, Eustache F, Piolino P (2011) Mental time travel into the past and the future in healthy aged adults: an fMRI study. Brain Cogn 75:1-9.

Virtue S, Haberman J, Clancy Z, Parrish T, Jung Beeman M (2006) Neural activity of inferences during story comprehension. Brain Res 1084:104-114.

Voss JL, Warren DE, Gonsalves BD, Federmeier KD, Tranel D, Cohen NJ (2011) Spontaneous revisitation during visual exploration as a link among strategic behavior, learning, and the hippocampus. Proc Natl Acad Sci U S A 108:E402-E409.

Ye Z, Zhou X (2009) Conflict control during sentence comprehension: fMRI evidence. Neuroimage 48:280-290. 